INTIQAD: JURNAL AGAMA DAN PENDIDIKAN ISLAM

ISSN 1979-9950 (print) || ISSN 2598-0033 (online), http://jurnal.umsu.ac.id/index.php/intiqad DOI: 10.30596/intiqad.v12i2.5263

Vol. 12, No. 2 (December 2020)

\title{
PERDA Baca Tulis al-Qur'an: Studi terhadap Respon Wali Nagari dalam Meningkatkan Pendidikan Agama di Talu
}

\author{
Ronaldi $^{*}$, Ahmad Lahmi ${ }^{2}$ Mursal $^{3}$ \\ Universitas Muhammadiyah Sumatera Barat*1, 2,3 \\ ${ }^{*}$ email:sagonaldi@gmail.com \\ 2email: damhaimhal@yahoo.com \\ ${ }^{2}$ email: $\underline{\text { mursalsaiqin@gmail.com }}$
}

\begin{abstract}
The local government has the authority to take policy, as has the Regent of West Pasaman period 2007 has taken policies related to improving the reading ability of the Qur'an for every child in the government area he leads. This research will trace how the regent responded in enforcing perda No. 9 year 2007 so as to give birth to a generation that is able to read the Qur'an well and have sufficient religious understanding. The design of this study is qualitative, while the data sources that researchers use are nagari guardians, purposively selected citizens, community leaders, according to the desired data then in this study used data collection techniques in the form of observations, interviews and documentation studies. The results of the study prove that: first, Wali Nagari has a positive response, the indicator is the instruction of the guardian agari to all citizens to submit their children to the mosque and mushalla to get a reading education writing the Qur'an, renovate the mosque and mushalla to be worthy as a place to learn to read the Qur'an, complete the necessary facilities, give appreciation to the teachers paying in every mosque and mushalla that is in Talu nagari. Second, children's understanding of Islamic religious education has increased since the regulation of the area was established.
\end{abstract}

\section{Keywords: Local Regulation, Reading And Writing Quran, Islamic Education.}

\section{Abstrak}

Pemerintah daerah memiliki wewenang untuk mengambil kebijakan, seperti halnya Bupati Pasaman Barat periode 2007 telah mengambil kebijakan yang terkait dengan peningkatan kemampuan membaca al-Qur'an bagi setiap

Artikel Info

Received:

04 August 2020

Revised:

21 October 2020

Accepted:

26 November 2020

Published:

03 December 2020 
anak di wilayah pemerintahan yang dipimpinnya. Penelitian ini akan menelusuri bagaimana respon wali nagari dalam menegakkan PERDA No. 9 Tahun 2007 sehingga melahirkan generasi yang mampu membaca al-Qur'an dengan baik serta memiliki pemahaman agama yang cukup. Desain penelitian ini ialah kualitatif, sementara sumber data yang peneliti gunakan ialah wali nagari, warga masyarakat yang dipilih secara purposive, tokoh masyarakat, sesuai dengan data yang diinginkan maka dalam penelitian ini digunakan teknik pengumpulan data berupa observasi, wawancara dan studi dokumentasi. Hasil penelitian membuktikan bahwa: pertama, Wali Nagari memiliki respon yang positif, indikatornya adalah instruksi wali agari kepada seluruh warga agar menyerahkan anaknya ke masjid dan mushalla untuk mendapatkan pendidikan baca tulis alQur'an, merenovasi masjid dan mushalla agar layak dijadikan sebagai tempat belajar baca tulis al-Qur'an, melengkapi sarana yang dibutuhkan, memberikan penghargaan kepada guru mengaji di setiap masjid dan mushalla yang ada di nagari Talu. Kedua, pemahaman anakanak terhadap pendidikan agama Islam terlihat meningkat sejak ditegakkannya peraturan daerah tersebut.

Kata Kunci: PERDA, BTQ, Pendidikan Agama Islam.

\section{A. Pendahuluan}

Pandai membaca maupun menulis bahkan memahami al-Qur'an bagi setiap muslim merupakan kewajiban (Ritonga, 2016), (Supriyadi \& Julia, 2019), (Noh \& Huda, 2020). Untuk itu, pemerintah daerah pada beberapa wilayah yang memiliki penduduk mayoritas muslim mengambil sebuah kebijakan yang terkait dengan peningkatan kemampuan warga masyarakat dalam membaca alQur'an. Hal ini dibuktikan dengan hasil penelitian yang cukup banyak terkait dengan PERDA di wilayah Indonesia bidang baca tulis al-Qur'an, seperti halnya hasil penelitian yang menelusuri berbagai perda terkait dengan kemampuan baca tulis al-Qur'an (Hayadin, 2011).

Penelitian lainnya ialah berkaitan dengan apresiasi pemerintah daerah kepada guru-guru TPQ/TQA serta MDA dengan memberikan bantuan kepada mereka walaupun dalam jumlah yang tidak banyak serta bentuk pengelolaan lembaga pendidikan yang berbasiskan 
INTIQAD: JURNAL AGAMA DAN PENDIDIKAN ISLAM

ISSN 1979-9950 (print) || ISSN 2598-0033 (online), http://jurnal.umsu.ac.id/index.php/intiqad

DOI: 10.30596/intiqad.v12i2.5263

Vol. 12, No. 2 (December 2020)

al-Qur'an (Hakim, Ritonga, Khadijah, et al., 2020). Studi yang berkaitan dengan analisis peraturan daerah tentang baca tulis al-Qur'an yang menyimpulkan adanya kesesuaian antara perda dengan kurikulum nasional pada berbagai aspek (Hayadin, 2013). Mahdi dalam penelitiannya pemberlakuan perda sampai pada tahun 2015 masih dalam tahap sosialisasi (Mahdi, 2013).

Terlepas dari beberapa temuan di atas, bisa membaca al-Qur'an bagi setiap orang Islam adalah langkah awal untuk memahami ajaran Islam (Nurlaili et al., 2020), karena al-Qur'an sebagai sumber ajaran Islam memuat berbagai hal yang dibutuhkan manusia dalam menjalankan kehidupan tanpa melanggar aturan Allah yang telah ditetapkan (Ritonga, 2015). Oleh karena itu, pemerintah daerah yang memiliki kesadaran akan pentingnya kemampuan membaca al-Qur'an bagi masyarakat sudah pasti akan mengambil sebuah kebijakan agar terkait dengan permasalahan tersebut.

Di antara dari sejumlah pemerintah daerah yang memiliki PERDA tentang pandai baca tulis al-Qur'an ialah Kabupaten Pasaman Barat, sebagaimana terlihat bahwa sejak 2007 Bupati Pasaman Barat telah mengambil kebijakan yang terkait dengan peningkatan kemampuan baca tulis alQur'an yang kemudian dtuangkan dalam PERDA No. 9 Tahun 2007. Keberadaan sebuah peraturan bagaimanapun bagusnya dapat dipastikan tidak akan berjalan dengan baik tanpa gerakan nyata dari pemerintahan level kelurahan, kenagarian maupun desa akan menjalankan dan mengawal kebijakan sampai pada masyarakat (Fadly et al., 2018), (Sitompul et al., 2020).

Berdasarkan pandangan di atas, Wali Nagari yang sejajar dengan Kepala Desa atau Lurah memiliki kedudukan yang penting dalam mensukseskan keterlaksanaan peraturan yang diambil oleh pihak pemerintah tingkat Kabupaten, provinsi bahkan tingkat Negara. Posisi kepemimpinan Wali Nagari semakin penting disebabkan level pemerintahan ini banyak berkomunikasi, berinteraksi bahkan bersosialisasi dengan masyarakat secara langsung. Dia banyak mengetahui apa yang terjadi di lingkungan sekitarnya (Asamoah, 2012), dia memiliki pengetahuan yang cukup tentang karakter masyarakat yang dipimpinnya, Wali Nagari dapat melihat peristiwa yang muncul di sekelilingnya. 
INTIQAD: JURNAL AGAMA DAN PENDIDIKAN ISLAM

ISSN 1979-9950 (print) || ISSN 2598-0033 (online), http://jurnal.umsu.ac.id/index.php/intiqad

DOI: 10.30596/intiqad.v12i2.5263

Vol. 12, No. 2 (December 2020)

Mengingat bahwa pemerintah level kenagarian sebagai ujung tombak dari implementasi sebuah peraturan daerah maka peneliti tertarik untuk melakukan analisis terhadap respon Wali Nagari terhadap PERDA. Disebabkan perda yang ingin dikaji ialah terkait dengan kemampuan baca al-Qur'an maka peneliti akan mengulas respon Wali Nagari tersebut dengan peningkatan pemahaman Pendidikan Agama Islam di Masyarakat. Secara vertical antara alQur'an dan pemahaman hal-hal yang berkaitan dengan ajaran agama Islam terdapat konektivitas yang kuat, karena dari al-Qur'anlah muncul hukum-hukum yang dijadikan acuan oleh umat Islam (Rahman et al., 2017), (GÖKKIR, 2008), (Fauziah et al., 2020).

Oleh karena terdapatnya hubungan yang kuat antara kemampuan membaca al-Qur'an dan pemahaman keislaman makan dalam penelitian ini akan difokuskan pada dua focus utama: pertama, respon Wali Nagari terhadap Peraturan Pemerintah Daerah yang berkaitan dengan Peningkatan Kemampuan Baca Tulis al-Qur'an. Kedua, peningkatan pemahaman masyarakat terhadap Pendidikan Agama Islam. Dengan menguraikan kedua focus penelitian ini diharapkan hasilnya akan memberikan informasi yang berharga bagi setiap pembaca dan terutama pemerintah tingkat Kenagarian dan masyarakat.

\section{B. Metode Penelitian}

Dalam rangka mencapai tujuan penelitian yang dijelaskan di atas, penelitian ini didesain dengan pendekatan kualitatif. Dasar pemilihan pendekatan ini ialah karena data yang dibutuhkan dalam penelitian ini berkaitan dengan kebijakan yang telah didokumentasikan serta realitas yang terjadi di tempat penelitian. Tempat yang dipilih untuk pelaksanaan penelitian ini ialah di Kenagarian Talu, tempat ini merupakan salah satu Kenagarian yang terdapat di Wilayah Pemerintahan Kabupaten Pasaman Barat, Sumatera Barat. Kenagarian Talu dipilih sebagai tempat penelitian dikarenakan masyarakat di kenagarian tersebut sebagaimana data di Kemenag Pasaman Barat memiliki kemampuan membaca al-Qur'an serta pemahaman ajaran Islam yang cukup baik, oleh karenanya bagaimana Wali Nagari Talu merespon PERDA No. 9 Tahun 2007 perlu untuk diekspos. 
INTIQAD: JURNAL AGAMA DAN PENDIDIKAN ISLAM

ISSN 1979-9950 (print) || ISSN 2598-0033 (online), http://jurnal.umsu.ac.id/index.php/intiqad

DOI: 10.30596/intiqad.v12i2.5263

Vol. 12, No. 2 (December 2020)

Sesuai dengan judul dan tujuan penelitian yang dijelaskan di atas, sumber penelitian ini terdiri dari Wali Nagari, Tokoh Masyarakat, Warga yang dipilih secara purposive. Sementara untuk mendapatkan data dari sumbersumber yang dijelaskan di atas, peneliti menggunakan tiga teknik pengumpulan data, yaitu: pertama, observasi, teknik ini dimaksudkan untuk megetahui secara langsung terhadap bagaimana Wali Nagari merespon PERDA No. 9, serta bagaimana masyarakat di sekitar Talu mengimplementasikan Perda tersebut dalam kehidupan mereka. Kedua, wawancara, penggunaan wawancara bertujuan untuk mendapatkan informasi yang terkait dengan respon Wali Nagari terhadap PERDA No. 9 dari Wali Nagari, Tokoh Masyarakat, serta warga secara langsung, oleh karenanya jenis wawancara yang digunakan ialah wawancara terbuka. Ketiga, Dokumentasi, peneliti menggunakan teknik ini dikarenakan banyak data yang dibutuhkan bersumber dari dokumen yang ada di tempat penelitian, dari dokumen-dokumen yang terkait akan dilakukan analisis yang berkaitan dengan respon Wali Nagari dan pemahaman masyarakat tentang Pendidikan Agama Islam.

Data yang didapatkan dari sumber penelitian sesuai dengan teknik pengumpulannya akan dianalisis dengan sesuai dengan analisis kualitatif yang ditawarkan Thomas dan Harden yang mengungkapkan mulai dari reduksi data, kemudian dilakukan klasifikasi dan setelah itu diambil kesimpulan (Thomas \& Harden, 2008). Teknik analisis ini dipandang tepat dalam penelitian ini karena semua data yang didapat baik melalui observasi atau wawancara maupun dokumentasi akan dilakukan cek keabsahan datanya melalui triangulasi. Sebelum adanya triangulasi peneliti tidak akan mengambil kesimpulan terhadap makna data.

\section{Hasil dan Pembahasan}

Perlu dijelaskan bahwa Nagari Talu merupakan salah satu Kenagarian yang dipimpin oleh pemerintah Wali Nagari, masyarakat sekitar sesuai dengan hasil pengamatan tergolong pada masyarakat yang memiliki tingkat religious yang cukup tinggi, hal itu terbukti dengan banyaknya kegiatan yang bernuansa keagamaan di lingkungan kenagarian, dan setiap jorong 
INTIQAD: JURNAL AGAMA DAN PENDIDIKAN ISLAM

ISSN 1979-9950 (print) || ISSN 2598-0033 (online), http://jurnal.umsu.ac.id/index.php/intiqad

DOI: 10.30596/intiqad.v12i2.5263

Vol. 12, No. 2 (December 2020)

memiliki rumah ibadah dalam hal ini Masjid dan Mushalla yang ramai dengan jamaah setiap waktu shalat. Dari pengamatan yang ada peneliti belum merasa puas dengan kondisi yang sebenarnya, sehingga peneliti melakukan wawancara dengan seorang warga dan dia menyatakan "masjid dan mushala di Kenagarian Talu pada umumnya ramai dengan jamaah, khususnya yang ada di Jorong ini kondisi seperti tadi adalah realita sehari-hari”.

Sesuai dengan kondisi yang digambarkan, bagaimana respon Wali Nagari dan Pemahaman masyarakat terhadap Pendidikan Agama Islam di Kenagarian Talu dapat dilihat sebagaimana di bawah ini: Respon Wali Nagari Talu Terhadap PERDA No. 9 Tahun 2007

Sebagaimana data yang telah dikumpulkan selama masa penelitian, terkait dengan respon Wali Nagari Talu terhadap PERDA dapat dilihat sebagaimana yang terdapat pada table 1 .

Table 1. Respon Wali Nagari terhadap PERDA

\begin{tabular}{|c|l|l|}
\hline No & Bentuk Respon & \multicolumn{1}{c|}{ Sumber } \\
\hline 1 & Sosialisasi & $\begin{array}{l}\text { Dokumen, } \\
\text { wawancara }\end{array}$ \\
\hline 2 & $\begin{array}{l}\text { Renovasi } \\
\text { Masjid/Mushala }\end{array}$ & $\begin{array}{l}\text { Dokumentasi, } \\
\text { Observasi dan } \\
\text { Wawancara }\end{array}$ \\
\hline
\end{tabular}

\begin{tabular}{|c|l|l|}
\hline 3 & $\begin{array}{l}\text { Penempatan } \\
\text { Guru Mengaji }\end{array}$ & $\begin{array}{l}\text { Dokumentasi, } \\
\text { Wawancara }\end{array}$ \\
\hline 4 & $\begin{array}{l}\text { Melengkapi } \\
\text { sarana dan } \\
\text { prasarana }\end{array}$ & $\begin{array}{l}\text { Observasi dan } \\
\text { wawancara }\end{array}$ \\
\hline 5 & $\begin{array}{l}\text { Peningkatan } \\
\text { Kompetensi } \\
\text { Guru TPQ/TQA } \\
\text { dan MDA }\end{array}$ & $\begin{array}{l}\text { Dokumentasi dan } \\
\text { Wawancara }\end{array}$ \\
\hline 6 & $\begin{array}{l}\text { Membuat } \\
\text { peraturan turunan } \\
\text { dari PERDA }\end{array}$ & $\begin{array}{l}\text { Dokumentasi dan } \\
\text { wawancara }\end{array}$ \\
\hline
\end{tabular}

Data yang terdapat pada table $1 \mathrm{di}$ atas dapat diinterpretasikan secara lebih jelas, yaitu:

Pertama, Sosialisai PERDA. Kegiatan sosialisasi perda No. 9 Tahun 2017 yang dilaksanakan oleh Pemerintah Nagari Talu, hal ini didukung oleh masyarakat Talamau sebagai berikut: Upaya yang dilakukan oleh Pemerintah Nagari Talu dalam mengoptimalisasikan implementasi Perda No. 9 Tahun 2007 tentang baca tulis al-Qur'an adalah dengan melakukan sosialisasi di tiap-tiap jorong dan sekolah di Nagari Talu agar masyarakat mengetahui Perda No. 9 tahun 2007 secara mendalam. Hal tersebut telah dilakukan oleh pemerintah Nagari Talu sejak Perda tersebut disyahkan tahun 2007.

Bentuk sosialisasi yang dilakukan pemerintah Nagari Talu sebagaimana diungkapkan oleh informan ialah dengan menyebarkan poin-poin penting dari 
PERDA tersebut ke wali Jorong, sekolah, masjid/mushala, serta menempelkannya pada papan informasi serta tempat yang sering dikunjungi masyarakat dan tempat berkumpulnya banyak orang. Informan lain menyebutkan bahwa sejak 2007 sampai saat ini Wali Nagari melalui Wali Jorong senantiasa melakukan sosialisasi PERDA kepada masyarakat di kenagarian Talu.

Sesuai dengan hasil wawancara di atas, dokumen yang terkait dengan sosialisasi juga masih ditemukan di beberapa Sekolah, di Kenagarian dan Masjid serta Mushalla, dokumen tersebut telah diarsipkan pihak sekolah dalam file arsip penting, di kenagarian juga telah menjadi arsip yang selalu diphoto kopi dan dipampang pada papan informasi setiap awal tahun, sementara beberapa masjid/mushalla menyimpan dokumen tersebut sebagai arsip.

Bentuk respon Wali Nagari sebagaimana yang telah diuraikan di atas adalah bentuk respon yang positif dari seorang pemimpin terhadap aturan yang dikeluarkan oleh atasannya. Pernyataan ini sesuai dengan kesimpulan yang disampaikan oleh Kartika yang menyatakan bahwa setiap peraturan dibutuhkan sosialisasi yang kontiniu agar mendapatkan pemahaman yang jelas bagi semua stakeholder (Kartika, 2019). Jauh sebelumnya Boyd pada Tahun 1917 telah mengingatkan bawa hukum serta segala hal-hal yang mengandung unsur kebijakan tidak akan terlaksana tanpa adanya sosialisasi yang berkesinambungan (Boyd, 1917).

Kedua, bentuk respon wali Nagari Talu terhadap PERDA No. 9 Tahun 2007 ialah dengan melakukan renovasi terhadap masjid dan mushalla.

Pengamatan telah dilakukan terhadap Masjid dan Mushalla yang ada di Nagari Talu, bahwa setiap masjid dan mushalla layak untuk disinggahi, hal itu dikarenakan keterjagaan kebersihan masjid dan lingkungan sekitarnya. Melihat kondisi masjid dan mushalla tersebut telah dilakukan wawancara dengan salah seorang tokoh masyarakat yang juga salah satu dari pengurus masjid di Jorong Talamau dia mengatakan, "sejak tahun 2008 Wali Nagari menginstruksikan agar setiap pengurus masjid dan mushalla yang ada di Kenagarian Talu untuk melakukan renovasi terhadap masjid atau mushalla yang sudah layak direnovasi, pencarian dana akan difasilitasi oleh pemerintah Wali Nagari sesuai kewenangannya”. 
INTIQAD: JURNAL AGAMA DAN PENDIDIKAN ISLAM

ISSN 1979-9950 (print) || ISSN 2598-0033 (online), http://jurnal.umsu.ac.id/index.php/intiqad

DOI: 10.30596/intiqad.v12i2.5263

Vol. 12, No. 2 (December 2020)

Ungkapan pengurus masjid seperti yang dituangkan di atas ternyata sesuai dengan dokumen yang diperoleh dari kantor wali Nagari, di mana dalam dokumen tersebut terdapat himbauan kepada seluruh wali Jorong dan Pengurus Masjid atau Mushalla untuk menyusun proposal perbaikan masjid atau mushalla sesuai dengan yang dibutuhkan, adapun sasaran pengiriman proposal itu akan difasilisitasi oleh pemerintah Kenagarian.

Terkait dengan temuan ini, karena PERDA yang direspon oleh Wali Nagari adalah kemampuan membaca al-Qur'an maka sesuai dengan fungsi masjid dan mushalla bagi masyarakat di Kenagarian Talu menunjukkan respon Wali Nagari sudah tepat. Karena sesuai dengan hasil observasi masjid dan mushalla di Kenagarian tersebut selain berfungsi sebagai tempat ibadah lima kali dalam sehari semalam juga difungsikan sebagai tempat belajar al-Quran bagi anak-anak, bahkan setiap masjid dan mushalla memiliki TPQ/TQA serta MDA yang lebih difokuskan untuk mempelajari alQur'an dan pendidikan agama Islam.

Ketiga, untuk merespon PERDA No. 9 Tahun 2007 wali nagari Talu juga melakukan perekrutan terhadap guru- guru yang akan ditempatkan di masjid dan mushalla. Dalam hal melakukan perekrutan ini, sebagaimana hasil wawancara dengan informan dia menyetakan wali nagari terlebih dahulu melakukan survey terhadap masjid dan mushalla, ketika masjid atau mushalla belum memiliki ustaz atau guru mengajinya masih kurang maka dikomunikasikan dengan pengurus masjid atau mushalla serta wali Jorong tentang kebutuhan guru mengaji.

Hasil wawancara tersebut sejalan dengan dokumen yang ditemukan di kenagarian yang memuat tentang himbauan kepada pengurus masjid dan mushalla serta wali Jorong tentang inventarisasi kebutuhan guru di TPQ/TQA dan MDA. Dari dokumen yang tersedia juga dilakukan wawancara dengan informan tentang criteria guru yang akan ditempatkan, dari hasil wawancara diketahui bahwa warga yang tinggal di sekitar masjid dan mushalla adalah menjadi prioritas, yang terpenting memiliki kemampuan dalam hal membaca al-Qur'an serta memiliki wawasan bidang pendidikan agama Islam.

Langkah yang diambil wali nagari Talu dalam merespon PERDA No. 9 
ISSN 1979-9950 (print) || ISSN 2598-0033 (online), http://jurnal.umsu.ac.id/index.php/intiqad

DOI: 10.30596/intiqad.v12i2.5263

Vol. 12, No. 2 (December 2020)

Tahun 2007 seperti yang dijelaskan di atas merupakan langkah yang bagus, karena sesuai hasil wawancara dengan informan diketahui bahwa sebelum adanya kebijakan tersebut banyak masjid dan mushalla yang belum memiliki guru mengaji yang tetap, sehingga anak-anak di lingkungan masjid dan mushalla tersebut terkadang mengaji dan terkadang tidak, namun setelah diadakannya perekrutan guru TPQ/TQA serta MDA melalui instruksi wali Nagari semua masjid dan mushalla sudah memiliki guru mengaji yang siap setiap hari mengajari anak-anak, bahkan setiap hari ahad pagi suasana meriah dari masjid dan mushalla terdengar karena adanya kegiatan didikan subuh yang dibina oleh guru mengaji.

Keempat, wali nagari Talu juga memfasilisitasi pengurus masjid dan mushalla serta wali jorong agar melengkapi sarana dan prasarana yang dibutuhkan di masjid untuk mendukung kelancaran pembelajaran baca tulis alQur'an. Dari hasil pengamatan diketahui bahwa masjid dan mushalla yang ada di Kenagarian Talu memiliki sarana dan prasarana yang cukup untuk kelangsungan pembelajaran al-Quran, di mana terlihat adanya ruangan khusus seperti sekolah untuk proses belajar alQur'an, memiliki meja dan kursi yang memadai, papan tulis, kitab suci alQur'an yang tersusun secara rapi, bukubuku pelajaran agama Islam. Ada juga mushalla yang belum memiliki ruangan belajar baca tulis al-Quran secara khusus, namun di dalam mushalla tersisih tempat khusus belajar bagi anakanak yang dilengkapi dengan meja duduk serta papan tulis dan al-Qur'an serta buku-buku pelajaran agama Islam.

Menurut informasi yang diperoleh dari informan, keberadaan sarana dan prasarana yang memadai pada setiap masjid dan mushalla untuk belajar alQur'an ialah bersumber dari donatur tetap setiap masjid serta sumbangan sukarela dari kaum muslimin. Keberadaan donatur tetap pada setiap masjid dan mushalla sebagaimana ditemukan dalam dokumen ialah juga terkait dengan instruksi wali Nagari yang menyurati wali Jorong, pengurus masjid dan mushalla untuk menyusun donatur tetap masjid dan mushalla untuk bidang pendidikan.

Wali Nagari Talu sesuai dengan data di atas memberikan respon yang baik terhadap PERDA No. 9 Tahun 2007 dengan menguatkan posisi penting 
INTIQAD: JURNAL AGAMA DAN PENDIDIKAN ISLAM

ISSN 1979-9950 (print) || ISSN 2598-0033 (online), http://jurnal.umsu.ac.id/index.php/intiqad

DOI: 10.30596/intiqad.v12i2.5263

Vol. 12, No. 2 (December 2020)

lembaga pendidikan informal. Sarana dan prasarana dalam pendidikan merupakan salah satu aspek terpenting dalam rangka mencapai tujuan pendidikan secara maksimal (Hakim, Ritonga, \& Susanti, 2020), (Noer et al., 2020). Beberapa hasil penelitian telah mengungkapkan bahwa sarana dan prasarana yang memadai pada sebuah lembaga pendidikan akan dapat memberikan kenyamanan pelajar (Marmoah et al., 2019), mewujudkan kecintaan peserta didik terhadap lingkungan (Ford \& Alsup, 2018).

Selain itu, yang kelima, dalam merespon keberadaan PERDA No. 9 Tahun 2007 wali Nagari Talu juga melakukan kebijakan dalam bentuk peningkatan kompetensi guru TPQ/TQA dan MDA. Dalam hal ini, bentuk kegiatan yang dilakukan adalah dengan menghadirkan sekali dalam sepekan Qori-Qori terbaik di Kabupaten Pasaman Barat untuk memberikan pelatihan tilawah kepada guru-guru TPQ/TQA dan MDA yang ada di lingkungan kenagarian Talu. Sebagaimana yang diungkapkan oleh informan bahwa mereka mendapatkan pelatihan membaca al-Qur'an dari para Qori professional yang diundang oleh pemerintah wali Nagari.

Di samping langkah tesebut, guruguru TPQ/TQA dan MDA juga diberikan peningkatan kompetensi dengan mengutus mereka untuk setiap kegiatan yang berkaitan dengan keagamaan baik yang diselenggarakan oleh kecamatan, kabupaten bahkan provinsi. Guru TPQ/TQA dan MDA di Kenagarian Talu menurut informan adalah perpanjangan tangan dari wali nagari untuk setiap kegiatan yang berkaitan dengan bidang agama.

Dari hasil studi dokumentasi juga diketahui bahwa mayoritas guru TPQ/TQA dan MDA yang ada di kenagarian Talu telah mendapatkan sertifikasi, kepemilikan sertifikat sebagai guru TPQ/TQA dan MDA di Kabupaten Pasaman Barat secara umum dan Kenagarian Talu secara khsusu menunjukkan guru tersebut adalah professional dan layak menadapatkan pembiayaan dari pemerintah daerah sesuai aturan yang berlaku. Sesuai dengan data di atas, terlihat dalam hal ini respon wali nagari terhadap PERDA No. 9 Tahun 2007 telah mencapai kesejahteraan para pengajar al-Qur'an. Karena keberadaan sertifikasi sesuai 
INTIQAD: JURNAL AGAMA DAN PENDIDIKAN ISLAM

ISSN 1979-9950 (print) || ISSN 2598-0033 (online), http://jurnal.umsu.ac.id/index.php/intiqad

DOI: 10.30596/intiqad.v12i2.5263

Vol. 12, No. 2 (December 2020)

dengan hasil berbagai penelitian menunjukkan bukti perhatian pemerintah terhadap kesejahteraan para guru (Novita, 2019), (Tisnelly et al., 2020), (Nurhattati et al., 2020).

Bentuk respon wali Nagari yang keenam, sebagaimana hasil penelitian yang didapatkan ialah memunculkan peraturan baru sebagai turunan dari PERDA No. 9 Tahun 2007. Bentuk peraturan baru yang dibuatnya adalah bahwa setiap anak yang mesti melanjutkan SLTP di Kenagarian Talu harus mampu membaca al-Qur'an, dan juga setiap calon penganten di lingkungan Kenagarian Talu harus mampu membaca al-Qur'an. Dalam satu sisi aturan yang dibuatnya tidak sesuai dengan aturan pendidikan yang berlaku secara nasional, namun sesuai dengan dokumen yang ditemukan bahwa aturan tersebut mendapat dukungan yang positif dari dinas pendidikan kecamatan bahkan Kabupaten Pasaman Barat.

Kemampuan Masyarakat Talu dalam Bidang Pendidikan Agama Islam

Masyarakat yang peneliti maksud dalam hasil penelitian ini ialah masyarakat yang masih level usia sekolah Dasar dan mengikuti pembelajaran di TPQ/TQA dan MDA yang ada di lingkungan Kenagarian Talu. Sebagaimana hasil yang didapatkan selama penelitian diketahui bahwa anak-anak usia Sekolah Dasar di Kenagarian Talu memiliki kemampuan yang baik dalam bidang Pendidikan Agama Islam, pernyataan ini didasarkan pada bahwa anak dari Talu selalu mendapatkan penghargaan bidang tilawatil Qur'an untuk anak-anak tingkat kecamatan bahkan Kabupaten, tidak sedikit diantara anak utusan dari Nagari Talu yang memenangkan lomba pidato cilik di tingkat kecamatan, kemampuan mereka semakin terlihat dalam kegiatan didikan subuh.

Sesuai dengan dokumen yang peneliti temukan di kenagarian Talu, di sana terdapat setidaknya 8 (delapan) piagam penghargaan untuk anak-anak dalam lomba musabaqah tilawatil Qur'an, dokumen ini menunjuukan bahwa sejak tahun 2007 (penerapan perda) sampai 2019 (waktu penelitian) anak-anak utusan dari talu selalu menjadi pertimbangan dan rival yang berat bagi kontingen lain di tingkat kecamatan sampai pada tingkat Kabupaten.

Memenangkan musabaqah tilawatil Qur'an dapat dijadikan sebagai salah 
INTIQAD: JURNAL AGAMA DAN PENDIDIKAN ISLAM

ISSN 1979-9950 (print) || ISSN 2598-0033 (online), http://jurnal.umsu.ac.id/index.php/intiqad

DOI: 10.30596/intiqad.v12i2.5263

Vol. 12, No. 2 (December 2020)

satu indicator tentang kualitas

terhadap ajaran agama apa yang

pemahaman umat Islam terhadap ajaran disampaikannya (Takriti et al., 2006), agamanya yang dalam hal ini Pendidikan Agama Islam, karena dari dalam alQur'an yang dibacanya lahir hukumhukum yang megatur kehidupannya di dunia, baik dalam aspek sebagai hamba Allah maupun aspek social (Ritonga et al., 2020).

Kemudian dari pada itu, anak-anak dari kenagarian Talu juga sering mendapatkan penghargaan dalam lomba PILDACIl (Pidato Cilik) baik yang diadakan pada level kecamatan maupun level Kabupaten. Realita ini menunjukkan bahwa anak-anak yang belajar di TPQ/TQA dan MDA yang ada di kenagarian Talu memiliki pemahaman bidang Pendidikan agama Islam yang cukup baik. Kemampuan pemahaman ini erat kaitannya dengan respon Wali Nagari terhadap PERDA No. 9 Tahun 2007, karena tanpa adanya dorongan dan respon positif pemerintah Kenagarian terhadap PERDA tersebut dapat dipastikan penyelenggaraan pendidikan di TPQ/TQA tidak akan seperti yang ada pada saat ini. Kemampuan anak dalam menyampaikan pesan-pesan keagaamaan adalah bukti bahwa anak tersebut memiliki pengetahuan yang baik (Ganjvar, 2019).

Tingkat pengetahuan anak-anak di kenagarian Talu terhadap Pendidikan Agama Islam juga terlihat dalam kemampuan mereka menjalankan tugas masing-masing pada setiap kegiatan didikan subuh. Sebagaimana hasil pengamatan peneliti diketahui bahwa di antara anak-anak ada yang bertugas pembawa acara, pembaca ayat suci alQur'an, membaca ayat-ayat pendek, membaca doa sehari-hari, membacakan puisi, berpidato, hafalan hadis-hadis nabi sampai pada membaca do'a. dari hasil pengamatan terlihat bahwa semua anak lancer dalam menjalankan tugasnya pada kegiatan didikan subuh. Kondisi demikian menjadi indicator bahwa anakanak di kenagarian Talu memiliki pengeatahuan yang baik dalam bidang pendidikan agama Islam.

\section{Simpulan}

Dari data yang telah diuraikan dalam pembahasan dapat disimpulkan bahwa respon wali nagari Talu terhadap PERDA No. 9 Tahun 2007 terlihat positif, pernyataan ini dibuktikan dengan sikap bijak, sikap cepat dan tepat yang 
INTIQAD: JURNAL AGAMA DAN PENDIDIKAN ISLAM

ISSN 1979-9950 (print) || ISSN 2598-0033 (online), http://jurnal.umsu.ac.id/index.php/intiqad

DOI: 10.30596/intiqad.v12i2.5263

Vol. 12, No. 2 (December 2020)

diambil oleh Wali Nagari dalam merealisasikan tercapainya tujuan yang telah diamanahkan pada PERDA yang ada. Dari respon positif yang ditunjukkan oleh Wali Nagari Talu memberikan dampak yang baik terhadap pengetahuan keagamaan warga khususnya anak-anak yang ada di lingkungan Kenagarian Talu, berbagai kebijakan yang diambil Wali Nagari telah melahirkan anak-anak yang memiliki pengetahuan yang baik dalam bidang pendidikan agama Islam.

\section{E. Daftar Pustaka}

Asamoah, K. (2012). A qualitative study of Chieftaincy and Local Government in Ghana. Journal of African Studies and Development Vol., $\quad 4(3), \quad 90-95$. https://doi.org/10.5897/JASD11.08 9

Boyd, J. H. (1917). Socialization of the Law. The University of Chicago Press, 22(6), 822-837.

Fadly, M., Supriatna, T., Mulyati, D., \& Simangunsong, F. (2018). The Local Government Strategy in SubDistrict Development as the Center of Economic Development with One Sub-District One Product Based at Mukomuko Region in Bengkulu Province. Journal of Public Administration and Governance, $\quad 8(3), \quad 374-387$. https://doi.org/10.5296/jpag.v8i3.13 545

Fauziah, R., Ritonga, M., \& Alrasi, F. (2020). Korelasi Tsiqah Tahfidz AlQur'an dengan Maharah al-Lughah al-'Arabiyyah Mustawa Tsalits Ma'had Az-Zubair bin Al-Awwam. EL-TSAQAFAH Jurnal Jurusan PBA, 19(1), 25-36. https: journal.uinmataram.ac.id/index.php /eltsaqafah\%0AKORELASI

Ford, A. Y., \& Alsup, P. (2018). Planning Science Classroom Facilities and Resources to Improve Students' Attitudes. Educational Planning, 24(4), 27-48.

Ganjvar, M. (2019). Islamic Model of Children's Spiritual Education (CSE); its influence on improvement of communicational behaviour with non-coreligionists. International Journal of Children's Spirituality, 24(2), 124-139. 


\section{INTIQAD: JURNAL AGAMA DAN PENDIDIKAN ISLAM}

ISSN 1979-9950 (print) || ISSN 2598-0033 (online), http://jurnal.umsu.ac.id/index.php/intiqad

DOI: 10.30596/intiqad.v12i2.5263

Vol. 12, No. 2 (December 2020)

https://doi.org/10.1080/1364436X.2

019.1624254

GÖKKIR, N. (2008). Dialectic Relationship between The Quran and Society In Islamic Hermeneutical Traditions. Süleyman Demirel Üniversitesi Ilahiyat Fakültesi Dergisi Review of the Faculty of Divinity, University of Süleyman Demirel, 1(20), 1-23.

Hakim, R., Ritonga, M., Khadijah, \& Susanti, W. (2020). Implementation of Contextual Teaching and Learning in Islamic Education at Madrasah Diniyah. Journal of Advanced Research in Dynamical \& Control Systems, 12(02), 33263332.

https://doi.org/10.5373/JARDCS/V 12I2/S20201455

Hakim, R., Ritonga, M., \& Susanti, W. (2020). Institute Quality Improvement Through Management Training of Accreditation Preparation in TK Aisyiyah Bustanul Athfal Padang. Advances in Social Science, Education and Humanities Research, Volume 449 Proceedings of the International Conference of Early Childhood Education (ICECE 2019), 44(Icece 2019), 55-65. https://doi.org/https://doi.org/10.29

91/assehr.k.200715.012

Hayadin. (2011). Implementasi Kebijakan Pemerintah Daerah tentang Kemampuan Baca-Tulis AlQur'an. EDUKASI Jurnal Penelitian Pendidikan Agama Dan Keagamaan, 9(1), 4368-4390.

Hayadin. (2013). Kesesuaian Isi Peraturan Daerah Kabupaten Banjar No. 04 Tahun 2004 tentang Baca Tulis al-Qur'an dengan Kurikulum Nasional Pendidikan Agama Islam. EDUKASI Jurnal Penelitian Pendidikan Agama Dan Keagamaan, 11(04), 33-45.

Kartika, A. W. (2019). Urgency of Socialization Regulation Regarding Establishment of Village Regulations. UNTAG Law Review (ULREV), 3(2), 178-187. http://jurnal.untagsmg.ac.id/indeks. php/ulrev/indeks

Mahdi, I. (2013). Kebijakan Pemerintah Daerah dalam Mengentaskan Buta Baca Al-Qur'an (Persiapan 
INTIQAD: JURNAL AGAMA DAN PENDIDIKAN ISLAM

ISSN 1979-9950 (print) || ISSN 2598-0033 (online), http://jurnal.umsu.ac.id/index.php/intiqad

DOI: 10.30596/intiqad.v12i2.5263

Vol. 12, No. 2 (December 2020)

Penerapan Perda No. 5 Tahun 2014

tentang Wajib Bisa Baca al-Qur'an

Bagi Siswa dan Calon Penganten di

Kabupaten Bengkulu Tengah).

Manhaj, 1(3), 17-26.

Marmoah, S., Adela, D., \& Fauziah, M. (2019). Implementation of Facilities and Infrastructure Management in Public Elementary Schools. AlTanzim: Jurnal Manajemen Pendidikan Islam, 03(01), 102-134. https://ejournal.unuja.ac.id/index.ph p/al-tanzim

Noer, S. M., Ritonga, M., Ekawati, R., Septiana, V. W., \& Susanti, D. (2020). Compact Disc Interactive Design Tutorial and Effect on the Improvement of Learning Network Computer Lessons. Nternational Journal of Advanced Science and Technology, 29(8), 457-467.

Noh, A. C., \& Huda, M. (2020). Understanding The Quran Resources as Main Principle for Family Institution in Islamic Education. Journal of Critical Reviews, $\quad 7(2), \quad$ 688-692. https://doi.org/http://dx.doi.org/10.3 1838/jcr.07.02.126
Novita, P. (2019). What Happened to Initial Teacher Education in Indonesia? AReview of the Literature. European Journal of Social Sciences Education and Research, 6(3), 88-103.

Nurhattati, Matin, Buchdadi, A. D., \& Yusuf, C. F. (2020). Teacher Certification in Indonesia: An Education Policy Analysis. Universal Journal of Educational Research, 8(5), 1719-1730. https://doi.org/10.13189/ujer.2020.0 80508

Nurlaili, Ritonga, M., \& Mursal. (2020). Muroja'ah Sebagai Metode Menghafal al-Qur'an Studi Pada Rumah Tahfiz Yayasan Ar-Rahmah Nanggalo Padang. Menara Ilmu, $X I V(02), 73-82$.

Rahman, S. A., Baharuddin, N., Ahmad, H. bin, Baharun, H., Sempo, M. W., Saad, N. S. M., Muhammad, N. A. F., \& Nizah, M. A. M. (2017). Exploring the Level of Understanding the Content of Quran among Diverse Groups of People. Sains Insani, 2(1), 61-65. https://doi.org/10.33102/sainsinsani 
INTIQAD: JURNAL AGAMA DAN PENDIDIKAN ISLAM

ISSN 1979-9950 (print) || ISSN 2598-0033 (online), http://jurnal.umsu.ac.id/index.php/intiqad

DOI: 10.30596/intiqad.v12i2.5263

Vol. 12, No. 2 (December 2020)
. $\operatorname{vol} 2 \mathrm{no} 1.52$

Ritonga, M. (2015). Pandangan Para Ahli Bahasa tentang Bahasa Serapan dalam al-Quran. Afkaruna: Jurnal Ilmu-Ilmu Keislaman, 11(2), 160-267.

https://doi.org/10.18196/AIIJIS.201

5.

Ritonga, M. (2016). Bargaining Kata di Dalam Al Qur'an : Kontroversi Ahli Terhadap Bahasa al Qur'an. Akademika, 21(2), 229-254. http://e-

journal.metrouniv.ac.id/index.php/a kademika/article/view/466

Ritonga, M., Asrina, Widayanti, R., Alrasi, F., Julhadi, \& Halim, S. (2020). Analysis of Arabic Language Learning at Higher Education Institutions with MultiReligion Students. Universal Journal of Educational Research, 9(269), 4333-4339. https://doi.org/10.13189/ujer.2020.0 80960

Sitompul, F., Lumbanraja, P., \& Tarmizi, H. B. (2020). Effect of Good Governance Application against Public Satisfaction with
Excellent Service as an Intervening Variable in the Medan Tembung Sub-District Office. International Journal of Research and Review, $7(1)$ 244-252.

www.ijrrjournal.com

Supriyadi, T., \& Julia, J. (2019). The Problem of Students in Reading the Quran: A Reflective-Critical Treatment through Action Research. International Journal of Instruction, 12(1), 311-326.

Takriti, R. A., Barret, M., \& BuchananBarrow, E. (2006). Children's understanding of religion: Interviews with Arab-Muslim, Asian- Muslim, Christian and Hindu children aged 5-11 years. Mental Health, Religion \& Culture, 9(1), https://doi.org/10.1080/1367467051 2331335677

Thomas, J., \& Harden, A. (2008). Methods for the thematic synthesis of qualitative research in systematic reviews. BMC Medical Research Methodology, 10, 1-10. https://doi.org/10.1186/1471-22888-45 
INTIQAD: JURNAL AGAMA DAN PENDIDIKAN ISLAM

ISSN 1979-9950 (print) || ISSN 2598-0033 (online), http://jurnal.umsu.ac.id/index.php/intiqad DOI: 10.30596/intiqad.v12i2.5263

Vol. 12, No. 2 (December 2020)

Tisnelly, Ritonga, M., \& Rasyid, A. Education Journal, 3(1), 45-56. (2020). The Competency of Islamic https://jurnal.umsb.ac.id/index.php/ Education Teachers in Madrasah ruhama/article/view/1940/1616

Ibtidaiyah 1 West Pasaman After

Certification. Ruhama: Islamic 